\title{
Smart materials and Green Synthesis: The perfect match for the future
}

\author{
B.P. Backx ${ }^{1, *}$
}

${ }^{1}$ Universidade Federal do Rio de Janeiro, Campus Duque de Caxias, Rio de Janeiro, 25.255-030, Brazil

DOI: https://doi.org/10.34256/irjmt2132

Received: 12-03-2021, Accepted: 03-04-2021, Published: 10-04-2021

Abstract: Materials science seeks the development of new materials with optimized characteristics. The union of various areas as chemistry, physics, nanotechnology, biology, and medicine catalyzes news materials. Smart materials react to external stimuli by modifying their chemical, mechanical, magnetic, optical, electrical, thermal properties. They have superior efficiency to the materials currently available and promise many advantages to their consumers. However, smart materials must be associated with sustainable technological progress. As a result of highly evolved technologies and intense laboratory research, their final characteristics must be connected with sustainable protocols. In addition to a significant difference associated with a wide application in various areas as textile industry, construction, medicine, drugs delivery, microorganisms' detection, smart materials must not pollute from production to disposal, and more than that, they must seek compensation for the harmful effects of this evolution on nature. In this way, smart materials will be an excellent advantage for the future and the environment.

Keywords: Smart Materials, Material Science, Green Synthesis, Technologies, Environment.

\section{Introduction}

Materials science connects the areas of chemistry, physics, nanotechnology, biotechnology, and engineering. The search for understanding the functionality of existing materials and their physical, chemical, and biological properties catalyzes the development of new materials that have optimized functions, with eco-friendly syntheses and excellent efficiency. Thus, new products are established for new consumers [1].

Smart materials arise with the new vision of the connection between various experts to develop responsive materials, which are materials that dynamically respond to external stimuli. These materials represent a great innovation for different areas such as textile industries [2], constructions [3], development of materials for drug delivery [4], among others.

Countless studies in the recent literature seek new technologies associated with smart materials. Materials with shape memory, for example, can return to their original shape, even after having undergone external stimuli, such as thermal expansion and tension [5]. The chromoactive materials are being used a lot in optical sensors because they promote color changes after an external stimulus, such as temperature, $\mathrm{pH}$, pressure, allowing the detection of pollutants in water[6]. Nanosensors have broad applications in biology, detecting contaminated water, medicine through detecting malignant tumors and detecting microorganisms. These sensors have low-cost, fast synthesis routes and are highly sensitive and efficient [7]. Piezoelectric materials, such as piezoelectric ceramics, can convert electrical energy into mechanics and vice versa [8]. Magnetorheological materials modify their properties with magnetic fields, thus preventing vibrations in bridges and large buildings [9].

Observations of natural phenomena help in predicting new materials. The synthetic spider web is one of them. Its resistance, around five times greater than steel, still enables elasticity. Thus, the development of armor or bulletproof vests can be replaced by bulletproof clothing and fibers for surgical sutures with high resistance and lightly strained cables and cables but excellent resistance to traction [10].

Graphite, graphene, and reduced graphene oxide ( $\mathrm{rGO}$ ) and their multiple properties have several applications. Also, they can be associated with other materials, such as plastics, generating batteries with high autonomy and flexibility [11]; hybrids of graphene and metal oxides that produce efficient solar cells [12], flexible electronic devices [13], more resistant buildings due to improvements in the mechanical properties of graphene-modified cement [14]. The development of 
dressings promotes skin tissue regeneration based on supramolecular hydrogels with graphene with excellent mechanical performance and presenting antimicrobial activity [15]. Smart materials, such as nanomaterials, work efficiently for sensor platforms for microorganisms, including in the diagnosis of COVID19 [16].

\section{Green synthesis of Smart Materials}

Green chemistry sets out principles that establish criteria that must be followed in order for the final product to have a beneficial connection with the environment [17].

1. Avoid waste.

2. Low concentration of precursor.

3. Less dangerous chemical synthesis routes.

4. Use of safe chemicals and products.

5. Safe reaction conditions.

6. Increase energy efficiency.

7. Use renewable raw materials.

8. Avoid chemical derivation.

9. Use catalysts instead of stoichiometric reagents.

10. Design of chemicals and products to degrade after use.

11. Analysis in real-time to avoid pollution.

12. Minimize the potential for accidents

Based on these concepts and seeking to combine them with the development of smart materials, it is essential to establish that smart materials should have better features associated with what they were intended for and have their origin in green syntheses to respect these principles-previously mentioned, protecting the environment and humanity. Thus, the planet will integrally benefit from smart materials. Thus, the search for smart materials based on green synthesis is increasingly urgent so that the impact of consumerism does not generate damage to the environment.

The green synthesis of magnetite nanoparticles $\left(\mathrm{Fe}_{3} \mathrm{O}_{4}\right)$ using Chromolaena odorata root extract to produce an intelligent nanocomposite represents an advantage. In addition to being environmentally friendly, they are also responsible for stimuli [18]. The Green Synthesis of Zeolite / Fe2O3 Nanocomposites can act as an intelligent and non-toxic nanofertant following the precepts of green chemistry [19]. The antimicrobial efficiency for combating bacteria resistant to antibiotics and eradicating bacterial biofilms in a hospital environment was obtained by green synthesis from the essential oil of Eucalyptus globulus to produce zinc oxide nanoparticles[20]. Intelligent fabrics obtained through treatment with silver nanoparticles obtained by green synthesis are also widely studied. This is because protection against the proliferation of microorganisms in hospital environments is of paramount importance. The green synthesis of silver nanoparticles from Plinia Cauliflora extract showed efficiency, avoiding this proliferation[21]. A nanothermometer and chromium IV ion sensor was obtained by eco-friendly synthesis and has a wide temperature range from 5 to $65 \circ \mathrm{C}$ and high efficiency for detecting hexavalent chromium ions in water samples [22]. A biosensor based on a biopolymer and silver nanoparticles, synthesized by the green route, is an optical ammonia sensor for clinical diagnosis detection of ammonia level in biological fluids for several in humans [23]. And not only for ammonia, but the green route produces many biosensors to detect hydrogen peroxide, pollutants in the environment, microorganisms, gas sensors, and even malignant tumors [24-29].

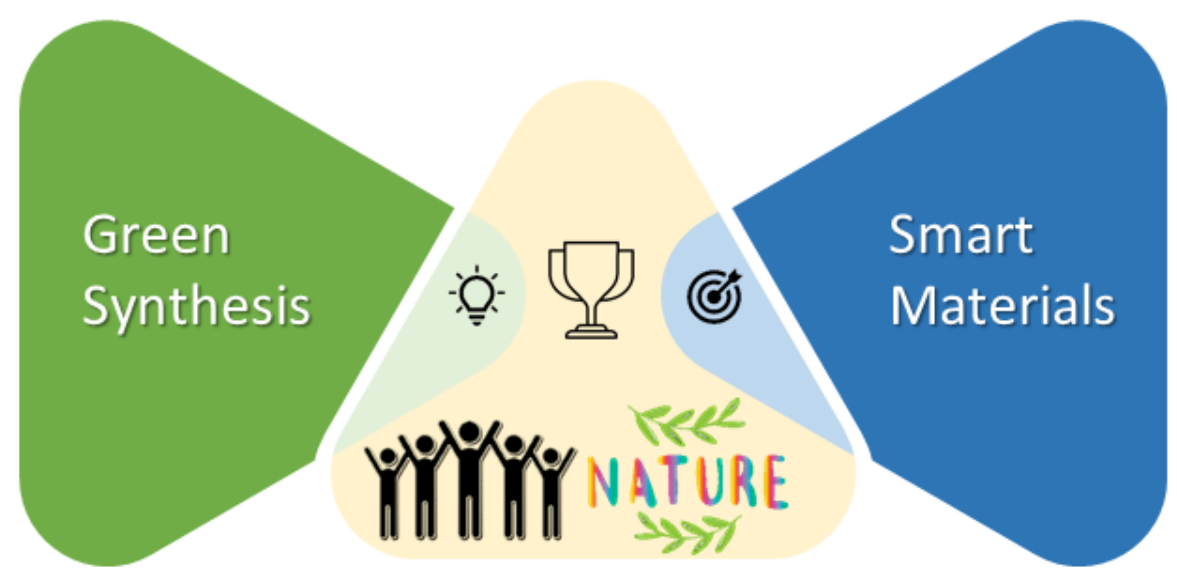

Figure 1. Smart Materials via green synthesis. 
Green synthesis of carbon-graphene nanotube hybrids demonstrated efficiency in water purification [30]. There is also the chemical modification with biodegradable molecules for the graphene hydrogel for gas detection [31]. For supercapacitors' flexible electronic applications, the green synthesis of autonomous cellulose/graphene oxide/polyaniline aerogel electrode is possible[32].

Given so many examples, it appears that the development of smart materials based in green chemistry, it is possible and desirable to apply these smart materials to connect their potential with the environment (Figure 1).

\section{Conclusion}

The revolution that smart materials can cause soon is incredible, and it is still challenging to predict the real impact of these new technologies on world society. However, humanity needs to understand that new materials must be based on eco-friendly products, from their synthesis, useful life, and disposal. The search for new materials must accompany the search of the world population. There is no point in having new materials, called smart, if humanity is not careful from its prospecting, synthesis, the study of useful life, and environmental impact. The scientific community must seek solutions for existing products, making them dynamic, efficient, and responsible for the environment, as the opposite will result in more consumerism and impact on nature. Smart materials should focus on implementing efficient technologies with environmental respect. Only then, not only will the materials be considered intelligent, but producers and consumers as well.

\section{References}

[1] William D. Callister Jr., David G. Rethwisch, (2020) Fundamentals of Materials Science and Engineering: An Integrated Approach, 5th Edition, John Wiley \& Sons, USA

[2] S. Schneegass, O. Amft, Introduction to Smart Textiles, Smart Textiles: Fundamentals, Design, and Interaction, Human-Computer Interaction Series, Springer International Publishing: Cham, (2017) 1-15.

[3] A.S.Y. Mohamed, Smart Materials Innovative Technologies in architecture; Towards Innovative design paradigm, Energy Procedia, 115 (2017) 139-154. http://doi:10.1016/..egypro.2017.05.014
[4] M. Sponchioni, U. Capasso Palmiero, D. Moscatelli, Thermo-responsive polymers: Applications of smart materials in drug delivery and tissue engineering, Materials Science and Engineering: C, 102 (2019) 589-605. http:// doi.org/10.1016/i.msec.2019.04.069

[5] W.M. Huang, Z. Ding, C.C. Wang, J. Wei, Y. Zhao, H. Purnawali, Shape memory materials, Materials Today, 13 (2010) 54-61. http:// doi.org/10.1016/S1369-7021(10)70128-0

[6] M. Ismail, M.I. Khan, K. Akhtar, M.A. Khan, A. M. Asiri, S.B. Khan, Biosynthesis of silver nanoparticles: A colorimetric optical sensor for detection of hexavalent chromium and ammonia in aqueous solution, Physica E: Lowdimensional Systems and Nanostructures, 103 (2018) 367-376. $\quad$ http:// doi.org/10.1016/i.physe.2018.06.015

[7] A. Lay-Ekuakille, A. Massaro, S.P. Singh, I. Jabłoński, M.Z.U. Rahman, F. Spano, Optoelectronic and Nanosensors Detection Systems: A Review, IEEE Sensors Journal, (2021) 1-1. http:// doi.org/10.1109/JSEN.2021.3055750

[8] Weiqi Qian, Weiyou Yang, Yan Zhang, Chris R. Bowen, Ya Yang, Piezoelectric Materials for Controlling Electro-Chemical Processes, NanoMicro Letters, $12 \quad$ (2020). https://doi.org/10.1007/s40820-020-00489-z

[9] S. Jerzy, Application of Smart Materials in Civil Engineering and Architecture, IOP Conference Series: Materials Science and Engineering, 958 (2020) 012006. http://doi.org/10.1088/1757899X/958/1/012006

[10] C. H. Bowen, B. Dai, C. J. Sargent, W. Bai, P. Ladiwala, H. Feng, W. Huang, D. L. Kaplan, J. M. Galazka, F. Zhang, Recombinant Spidroins Fully Replicate Primary Mechanical Properties of Natural Spider Silk, Biomacromolecules, 19 (2018) 3853-3860. http:// doi.org/10.1021/acs.biomac.8b00980

[11] H. Murata, Y. Nakajima, Y. Kado, N. Saitoh, N. Yoshizawa, T. Suemasu, K. Toko, Multilayer Graphene Battery Anodes on Plastic Sheets for Flexible Electronics, ACS Applied Energy Materials, 3 (2020) 8410-8414. http:// doi.org/10.1021/acsaem.0c01030

[12] K. Basu, G. S. Selopal, M. Mohammadnezad, R. Akilimali, Z. M. Wang, H. Zhao, F. Vetrone, F. Rosei, Hybrid graphene/metal oxide anodes 
for efficient and stable dye sensitized solar cell, Electrochimica Acta, 349 (2020) 136409. https://doi.org/10.1016/j.electacta.2020.136409

[13] R. You, Y.-Q. Liu, Y.-L. Hao, D.-D. Han, Y.-L. Zhang, Z. You, Laser Fabrication of GrapheneBased Flexible Electronics, Advanced Materials, 32 (2020) 1901981. http:// doi.org/10.1002/adma.201901981

[14] S.P. Dalal, P. Dalal, Experimental Investigation on Strength and Durability of Graphene Nanoengineered Concrete. Construction and Building Materials, $276 \quad$ (2021) 122236. https://doi.org/10.1016/j.conbuildmat.2020.122 $\underline{236}$

[15] H. Zhang, S. Zheng, C. Chen, D. Zhang, A graphene hybrid supramolecular hydrogel with high stretchability, self-healable and photothermally responsive properties for wound healing, RSC Advances, 11 (2021) 6367-6373. https://doi.org/10.1039/D0RA09106E

[16] Ö. Erdem, E. Derin, K. Sagdic, E. G. Yilmaz, F. Inci, Smart materials-integrated sensor technologies for COVID-19 diagnosis, Emergent Materials, (2021). http://doi.org/10.1007/s42247-020-00150-w

[17] B. Backx, Green nanotechnology: only the final product that matters?. Natural Product Research, 6(2020) 1-3. https://doi.org/10.1080/14786419.2020.185516 $\underline{8}$

[18] E. C. Nnadozie, P. A. Ajibade, Green synthesis and characterization of magnetite (Fe3O4) nanoparticles using Chromolaena odorata root extract for smart nanocomposite, Materials Letters, 263, (2020) 127145. https://doi.org/10.1016/i.matlet.2019.127145

[19] H. Jahangirian, R. Rafiee-Moghaddam, N. Jahangirian, B. Nikpey, S. Jahangirian, N. Bassous, B. Saleh, K. Kalantari, T. J. Webster, Green Synthesis of Zeolite/Fe2O3 Nanocomposites: Toxicity \& Cell Proliferation Assays and Application as a Smart Iron Nanofertilizer, International Journal of Nanomedicine, $15 \quad$ (2020) 1005-1020. http://doi.org/10.2147/IJN.S231679

[20] Z. Obeizi, H. Benbouzid, S. Ouchenane, D. Yılmaz, M. Culha, M. Bououdina, Biosynthesis of Zinc oxide nanoparticles from essential oil of Eucalyptus globulus with antimicrobial and antibiofilm activities, Materials Today Communications, 25 (2020) 101553. http:// doi.org/10.1016/j.mtcomm.2020.101553
[21] B. Pizzorno Backx, B. Rech Pedrosa, T. Delazare, F. R. D. Carmo Damasceno, O. A. Leitao Dos Santos, Green Synthesis of Silver Nanoparticles: A Study of the Dispersive Efficiency and Antimicrobial Potential of the Extracts of Plinia Cauliflora for Application in Smart Textiles Materials for Healthcare, Journal of Nanomaterials and Molecular Nanotechnology, $07 \quad$ (2018). $\quad$ http:// doi.org/10.4172/2324-8777.1000236

[22] L. Li, C. Shao, Q. Wu, Y. Wang, M. Liu, Green Synthesis of Multifunctional Carbon Nanodots and Their Applications as a Smart Nanothermometer and $\mathrm{Cr}(\mathrm{VI})$ Ions Sensor, Nano, $13 \quad$ (2018) $1850147 . \quad$ http:// doi.org/10.1142/S1793292018501473

[23] S. Pandey, G. K. Goswami, K. K. Nanda, Green synthesis of biopolymer-silver nanoparticle nanocomposite: An optical sensor for ammonia detection, International Journal of Biological Macromolecules, 51 (2012) 583589.

doi.org/10.1016/i.ijbiomac.2012.06.033

[24] C. K. Tagad, S. R. Dugasani, R. Aiyer, S. Park, A. Kulkarni, S. Sabharwal, Green synthesis of silver nanoparticles and their application for the development of optical fiber based hydrogen peroxide sensor, Sensors and Actuators B: Chemical, 183 (2013) 144-149.

https://doi.org/10.1016/i.snb.2013.03.106

[25] V. K. Shukla, R. S. Yadav, P. Yadav, A. C. Pandey, Green synthesis of nanosilver as a sensor for detection of hydrogen peroxide in water, Journal of Hazardous Materials, 213214 (2012) 161-166.

http://doi.org/10.1016/j.jhazmat.2012.01.071

[26] T.-H. Ko, S. Radhakrishnan, M.-K. Seo, M.-S. Khil, H.-Y. Kim, B.-S. Kim, A green and scalable dry synthesis of $\mathrm{NiCo2O4/graphene}$ nanohybrids for high-performance supercapacitor and enzymeless glucose biosensor applications, Journal of Alloys and Compounds, 696 (2017) 193-200.

https://doi.org/10.1016/j.jallcom.2016.11.234

[27]S. Ahmadian-Fard-Fini, M. Salavati-Niasari, D. Ghanbari, Hydrothermal green synthesis of magnetic Fe3O4-carbon dots by lemon and grape fruit extracts and as a photoluminescence sensor for detecting of $E$. coli bacteria, Spectrochimica Acta Part A: Molecular and Biomolecular Spectroscopy, 203 
(2018)

481-493.

https://doi.org/10.1016/j.saa.2018.06.021

[28] Le-Le Li, Wei-Ming Zhang, Quan Yuan, ZhenXing Li, Cheng-Jie Fang, Ling-Dong Sun, LiJun Wan, Chun-Hua Yan, Room Temperature Ionic Liquids Assisted Green Synthesis of Nanocrystalline Porous $\mathrm{SnO}_{2}$ and Their Gas Sensor Behaviors, Crystal Growth and Design, 8(2008) 4165-4172.

https://doi.org/10.1021/cg800686w

[29] N. González-Ballesteros, S. Prado-López, J. B. Rodríguez-González, M. Lastra, M. C. Rodríguez-Argüelles, Green synthesis of gold nanoparticles using brown algae Cystoseira baccata: Its activity in colon cancer cells, Colloids and Surfaces B: Biointerfaces, 153 (2017) 190-198.

http://doi.org/10.1016/j.colsurfb.2017.02.020

[30] Z. Sui, Q. Meng, X. Zhang, R. Ma, B. Cao, Green synthesis of carbon nanotube-graphene hybrid aerogels and their use as versatile agents for water purification, Journal of Materials Chemistry, 22 (2012) 8767-8771. http://doi.org/10.1039/C2JM00055E

[31] J. Wu, Y. Wei, H. Ding, Z. Wu, X. Yang, Z. Li, W. Huang, X. Xie, K. Tao, X. Wang, Green Synthesis of 3D Chemically Functionalized Graphene Hydrogel for High-Performance NH3 and NO2 Detection at Room Temperature, ACS Applied Materials \& Interfaces, 12 (2020) 20623-20632.

http://doi.org/10.1021/acsami.0c00578

[32] Y. Li, Z. Xia, Q. Gong, X. Liu, Y. Yang, C. Chen, C. Qian, Green Synthesis of Free Standing Cellulose/Graphene Oxide/Polyaniline Aerogel Electrode for High-Performance Flexible All-Solid-State Supercapacitors, Nanomaterials, 10 (2020) 1546.

\section{https://doi.org/10.3390/nano10081546}

\section{Acknowledgement}

Federal University of Rio de Janeiro, I will always be grateful!

\section{Funding}

No funding was received for conducting this study.

\section{Conflict of interest}

The Author has no conflicts of interest to declare that they are relevant to the content of this article.

\section{About the License}

(C) The author 2021. The text of this article is open access and licensed under a Creative Commons Attribution 4.0 International License
Cite this Article

B.P. Backx, Smart materials and Green Synthesis: The perfect match for the future, International Research Journal of Multidisciplinary Technovation, Vol 3, Iss 3 (2021) 7-11. DOI: https://doi.org/10.34256/irjmt2132 